\title{
Recent Advance on Torrefaction Valorization and Application of Biochar from Agricultural Waste for Soil Remediation
}

\author{
Kai Su*, Qirui Qin, Jingyu Yang, Linxiao Li and Shaoqi Deng \\ Faculty of Geosciences and Environmental Engineering, Southwest Jiaotong University, Chengdu, 611756, China \\ ${ }^{\star}$ Corresponding Author: Kai Su. Email: ksu@swjtu.edu.cn
}

Received: 02 July 2021 Accepted: 22 July 2021

\begin{abstract}
With the increase of global proportion of soil pollution and the number of areas at risk, researchers have sought to develop various pathways to repair or relieve the pollutants in soil. Among them, biochar represents one multidimensional soil amendment which has got great deal of attention on its physicochemical properties towards the removal or mitigation of contaminants in soil. A variety of agricultural wastes like straw and manure prepared from different torrefaction process have been employed as feedstock for the production of biochar, which can be applied to the contaminated soil to facilitate the growing environment for crops, and to improve soil fertility and microbial environment. In addition, the utilization of biochar for soil remediation is also considered as a process of carbon sequestration. The purpose of this review is to summarize the latest research progress in torrefaction processes and mechanism of agricultural waste, the effects of different torrefaction methods on the formation and properties of biochar were explained, coupled with the effects of process parameters. Especially, the conversion and mechanisms of biochar prepared from agricultural wastes composed mainly with lignocellulosic material were discussed, and the characteristics of biochar prepared for improving soil physical and chemical characteristics, microbial community characteristics, nutrients, and the stability and relief of soil pollutants, especially heavy metals, are compared. Finally, this work discussed the application and future technical challenges of soil remediation based on agricultural waste derived biochar.
\end{abstract}

\section{KEYWORDS}

Torrefaction; biochar; soil remediation; agricultural waste

\section{Introduction}

Soil contamination like heavy metals threatens the food chain globally, and the residence of the pollutants in the soil is generally permanent and cannot be dis-integrated through organic activity, and these result in poor crop yield and quality and the biomagnification endangers human health [1,2]. In recent years, biochar has attracted researchers for environmental remediation like the waste water treatment, catalysts, modified materials, and soil remediation. Especially, biochar has been considered an efficient technique to reduce or stabilize the contamination for soil. Meanwhile, the utilization of biochar for soil remediation is considered as a process of carbon sequestration [3]. One of the significant advantages of the biochar is that it can be prepared directly from agricultural waste like lignocellulose which is renewable resource and is widely defined as waste discharged from agricultural production, 
agricultural processing and poultry breeding and rural residents, while agricultural waste is mainly composed of lignocellulose materials and the derives. Torrefaction process can heat the raw material to certain temperature rapidly (high temperature, $600-1000^{\circ} \mathrm{C}$; low temperature, $\leq 600^{\circ} \mathrm{C}$ ) with no oxygen or lower than the theoretical oxygen environment, and the feedstock can be converted into liquid (20-40\%), noncondensable gas (10-20\%) and solid residue (40-60\%), which is carbon-rich and porous product, namely biochar [4]. By varying the parameters, the mass and $\mathrm{C}$ distribution can be controlled, coupled with the properties. In the past 10 years, the research related to biochar applications based on the multifunctional features has increased greatly [5-7].

The application of biochar to soil remediation has been extensively studied because the physical structure of biochar (high surface area and high porosity) can improve soil aeration and provide shelter for soil microorganisms by providing minerals and water [8,9]. Additionally, it has been proved that biochar contains suitable nutrients for plant and microbial growth, surface functionalities for the potentially toxic elements immobilization, and porous surface for partitioning/precipitation and microbial attachment. The surface of biochar is rich in functional groups, such as hydroxyl, ketone, ester, aldehyde and amino, and biochar exhibits hydrophilic/hydrophobic and acidic/alkaline properties. The presence of these groups on the surface of biochar can significantly improve the cation exchange capacity, nutrient retention capacity and water retention capacity of soil [5]. All of these properties can improve the soil fertility and increase crop yields. According to the biochar torrefaction process and conditions, various $\mathrm{pH}$, surface area, porosity and other physical and chemical characteristics have been investigated in terms of the utilization of biochar in different soil types (fertile, poor, sandy) [10]. Several studies also focused on the germination rate of seeds, and proved that soil remediation could indeed improve plant growth. However, few studies have been taken on if the application of biochar could reduce the germination rate [11]. In addition, long-term utilization of biochar in soil could lead to poor stability, and biochar may release toxic substances such as aromatic compounds nitrogen-containing heterocycles which remain in the form of biocrude-oil and also become the reason for the toxicity [12]. Thus, the toxicity risk of biochar should be in controlled. In this regard, it is crucial to avoid the risks biochar could bring to the soil and to take the best advantage of biochar.

In this review, we summarized the recent advance in torrefaction techniques of agricultural waste conversion processes and applications. We also compared the effects of process parameters, and the conversion and mechanisms of biochar derived from agricultural wastes of typical lignocellulosic material. Various characteristics of biochar prepared for cultivating soil physical and chemical characteristics including microbial community characteristics, nutrients, and the stability and remediation of soil pollutants like heavy metals were reviewed. Potential application in future and technical challenges of soil remediation based on agricultural waste derived biochar were presented, and a better balance between torrefaction and biochar application in soil remediation is excepted.

\section{Agricultural Wastes Torrefaction and Pathways}

\subsection{Components of Lignocellulose}

Since lignocellulose makes up the largest part of agricultural waste, lignocellulosic material is discussed in this review. Lignocellulose is a major component of natural biomass, produced by terrestrial plants, and is a sustainable and non-food resource, which is generally composed of $40-50 \%$ cellulose, $25-30 \%$ hemicellulosic and 15-20\% lignin, as well as inorganic and extractable substances with low molecular weight [13]. Fig. 1 shows the basic structure and components of lignocellulosic material. In general, the largest percentage of lignocellulose occupied by cellulose is made up of glucose unit, which is connected via the $\beta-1,4$ glycosidic bond [14]. Cellulose in lignocellulosic materials is usually divided into crystalline fiber parts and parts with disorganized and amorphous structures, and most of these cellulose chains are assembled into independent fiber structures and connected by weak hydrogen bonds. Hemicellulose is a 
complex pentose polymer, like xylose, and has a lower degree of polymerization than cellulose [15]. Several studies showed that hemicellulose could bind cellulose through hydrogen bonds, and form covalent bonds with lignin to enhance the rigidity of plant cell walls. At certain temperature, hemicellulose can be easily separated from the main constituents and decomposed into monomers. In general, hemicellulose consists of a variety of sugars (mainly xylan and glucomannan) containing short side chains, which make hemicellulose less thermally stable and more chemically degradable [16]. However, lignin represents one kind of biopolymer with three-dimensional network structure, which is composed of three methoxysubstituted phenylpropane units. Lignin is widely cross-linked to establish the stable skeleton of plant cell wall. It is the second largest biomass resource after cellulose. Lignin usually binds to hemicellulose through covalent bonds to avoid physical damage to plants and attack by microorganisms [17].
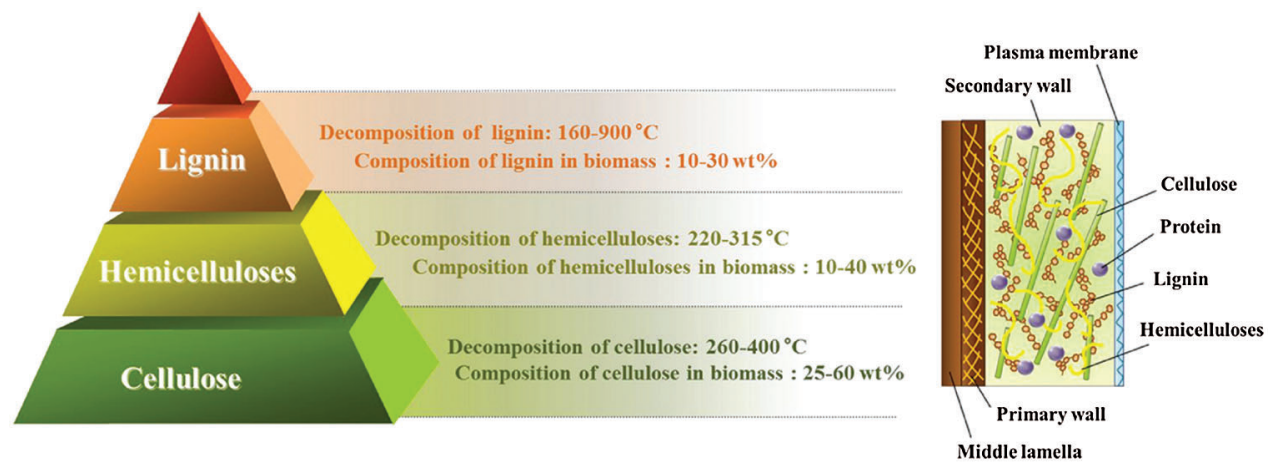

Figure 1: Structure and main components of lignocellulose [14]

\subsection{Typical Torrefaction Technologies}

Generally, torrefaction technologies mainly include slow torrefaction, fast torrefaction, catalytic torrefaction and microwave torrefaction, etc. Normally, biomass is heated at a slow or rapid rate. Though it is recommended that feedstock could be heated to residence temperature as quickly as possible, appropriate control of the heating rate is essential. For example, to analyze the conversion of agricultural waste and derived products, it is necessary to heat biomass at a relatively slow rate [18]. For the slow torrefaction, the steam stays in the reactor for $10-60 \mathrm{~min}$ and the heating rate ranges from $0.1-1 \mathrm{~s} /{ }^{\circ} \mathrm{C}$, and this is set for the formation of more biochar. Prabir Basu et al. divided slow torrefaction into two stages, the carbonization stage and the conventional stage [19]. During the carbonization process, biochar dominates the products. This stage was the most primitive form of torrefaction, during which the feedstock was slowly heated to a temperature of approximately $400^{\circ} \mathrm{C}$. During the conventional stage, the biomass was heated slowly to $600^{\circ} \mathrm{C}$ and the duration time was just few minutes. With the increase of temperature, the yield of bio-oil decreased gradually [19]. As shown in Fig. 2, a common slow torrefaction system includes fixed bed, condenser tubular furnace, generally with $\mathrm{N}_{2}$ supplied from the top to the reactor, and flowmeter is used to control the carrier gas flow. At a lower temperature range, biochar is the dominant product, while at higher temperatures, biogas occupies the most part of product. Increasing the temperature to about $500^{\circ} \mathrm{C}$ is the best temperature for bio-oil production. In conclusion, biochar is the main product of slow torrefaction, the yield of bio-oil in the whole process is about 30 $40 \%$, while the yield of biochar can reach about $60-70 \%$ for a slow torrefaction [20]. 


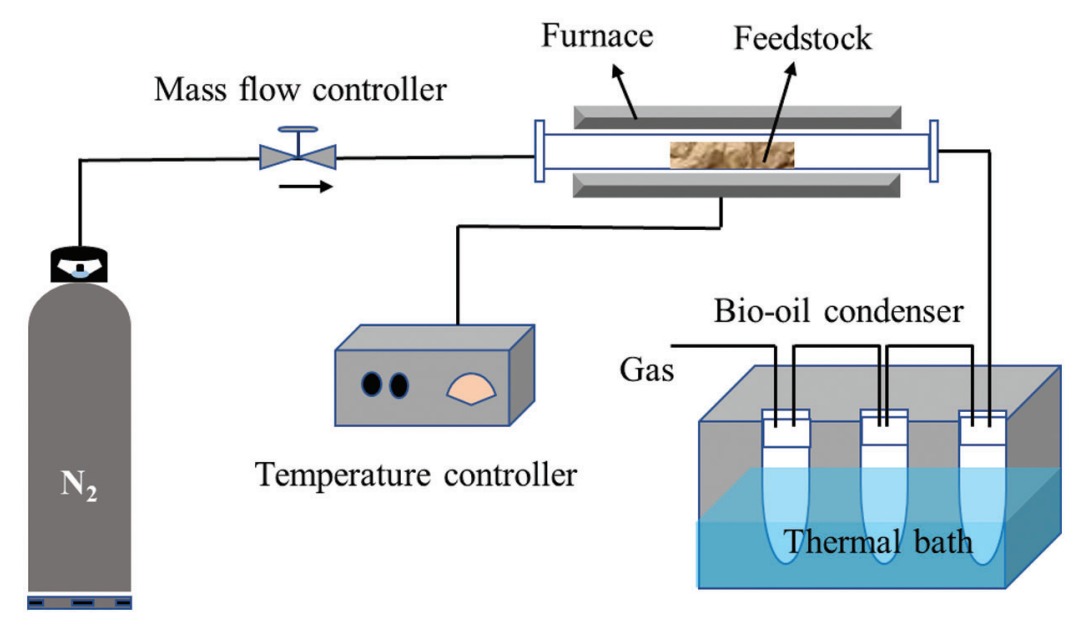

Figure 2: Schematic diagram slow pyrolysis system

The aim of fast torrefaction is to maximize the production of liquid product, which is easy to store and transport and has low nitrogen and sulfur content. In the fast torrefaction process, the biomass rapidly heats up and reaches the temperature before complete decomposition [21]. Therefore, fast torrefaction has advantages of fast heating rate, high reaction temperature, short duration time, fast heat transfer and steam cooling, etc. As bio-oil is the main product of fast torrefaction, the maximum temperature in most fast torrefaction processes must be less than $500^{\circ} \mathrm{C}$. Thus, the rate of heating is a critical factor that affects the yield of the liquid products, usually in the range of $5-40{ }^{\circ} \mathrm{C} / \mathrm{min}$. As shown in Fig. 3, a fluidized bed is usually used for fast torrefaction. Feedstock can be placed to the reactor from the top, and carrier gas is blown into the reactor from the bottom. The product is swept by carrier gas in a fluidized bed and then condensed by placing a condenser at the outlet [22].

Catalytic pyrolysis process is generally used in the preparation of bio-oil, since the feedstock degradation can be enhanced by using catalysts [23]. For example, bio-oil produced from biomass processing contains a large amount of oxygen, which decreases the heating value and decreases the stability of the oil due to polymerization and condensation reactions [24]. In addition, the utilization of catalysts can reduce ratio of nitrogen in bio-oil, because most torrefaction process uses nitrogen as carrier gas that can react with the feedstock. Studies have indicated that catalytic cracking technology could improve the properties of bio-oil [25]. Proper catalyst can change the reaction process and improve the quality of bio-oil such as flow performance and storage properties. Catalysts can be mixed in various ways and the degree of coalification and surface groups rely more on the catalysts. The schematic diagram of the catalytic torrefaction device is shown in Fig. 4 [26]. During the catalytic process, biomass is usually pyrolyzed by tubular fixator or packed reactor. An electric furnace is used for heating, and inert or carrier gas is used to keep the reactor at oxygen-free environment. In addition, inert gas can flow the steam to a condenser which is used for condensing the steam. Generally, two ways of catalytic pyrolysis are employed, namely catalytic bed and catalyst mixing method [25]. For the first one, feedstock and catalyst are inserted in stages, with quartz cotton used in the middle. The catalyst bed maintains a constant temperature with the steam passing. For the second way, the catalyst and feedstock are mixed in reactor, and the operating temperature is generally controlled between $300^{\circ} \mathrm{C}$ and $600^{\circ} \mathrm{C} \mathrm{[27].} \mathrm{The} \mathrm{study}$ and comparison of catalysts will not be described in detail here. 


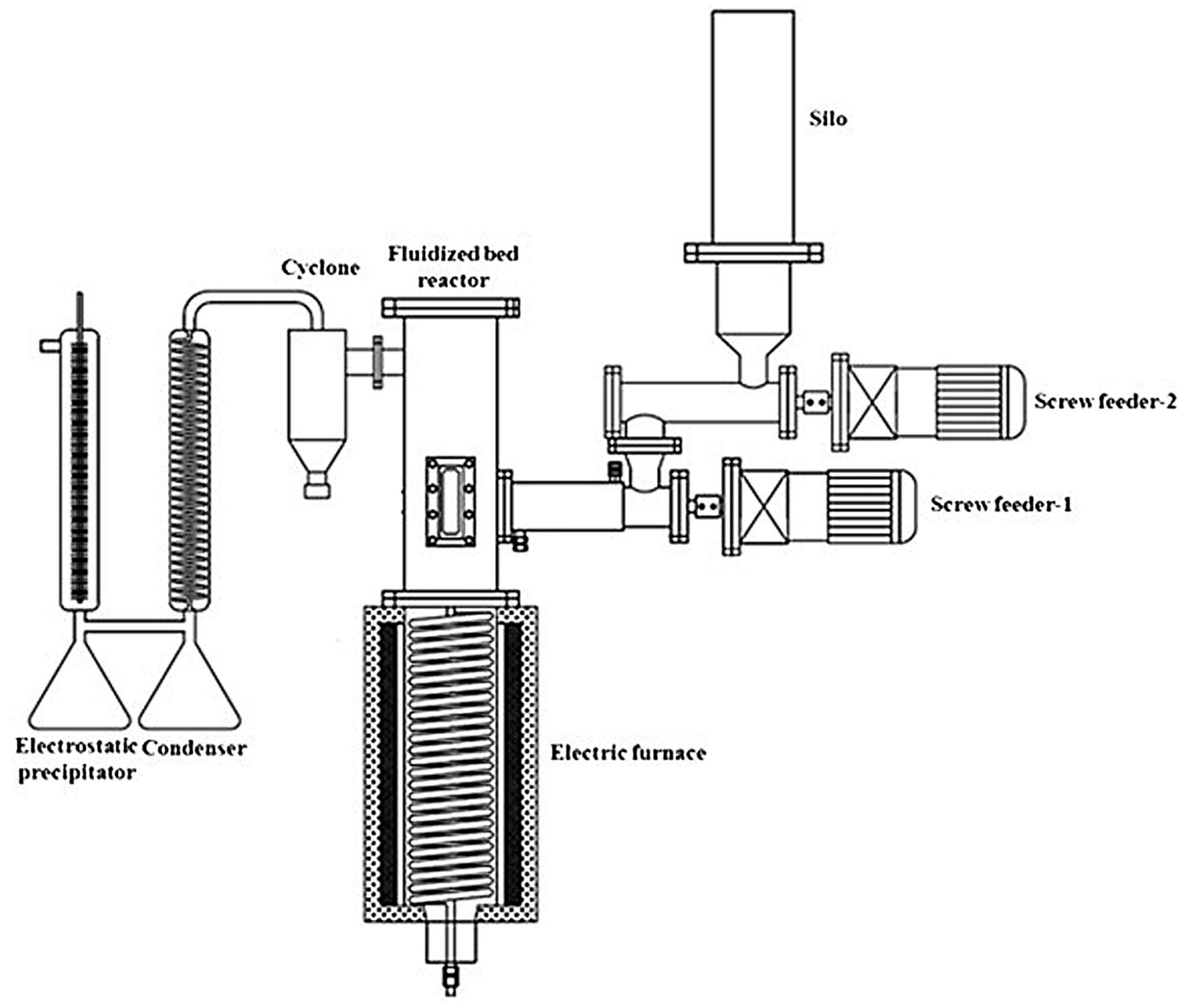

Figure 3: Schematic diagram of typical fast torrefaction system [22]

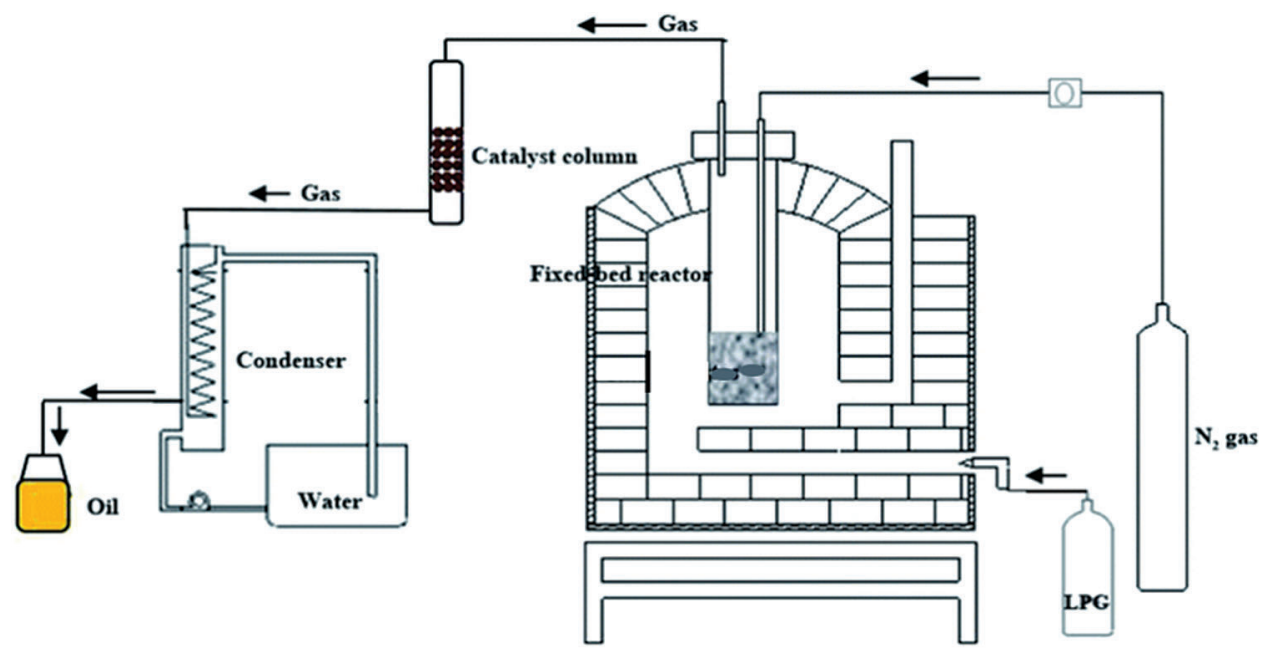

Figure 4: Schematic diagram of catalytic torrefaction system [23] 
Microwave torrefaction technology represents a new heating method which has received attentions in recent years because it permits heat to penetrate the feedstock evenly [28]. The representative microwave torrefaction experimental system is shown in Fig. 5 [29]. The system includes a microwave oven, a reactor, a condenser, a feeder, a gas feeder, a thermocouple and a liquid fractionator [30]. Before the running process, the feedstock can be added to the reactor and carrier gas is blown through the reactor to ensure that air is expelled from the device. As for other methods, the inert gas blows the pyrolysis steam to a condenser which is used for condensing the gas. In general, the biogas yield is higher than that of conventional methods [30]. In addition, compared with conventional torrefaction, the concentration of biogas and biohydrogen in gaseous products during microwave torrefaction is higher [31]. One of the most important is that large biomass pieces can be heated evenly, and the ash content in bio-oil is relatively low [32]. In addition, the process is easily controlled and does not require mixing or fluidizing devices. In conclusion, microwave torrefaction technology has high scalability and is suitable for biomass conversion with large volume. Four common biomass torrefaction systems are summarized in Tab. 1.

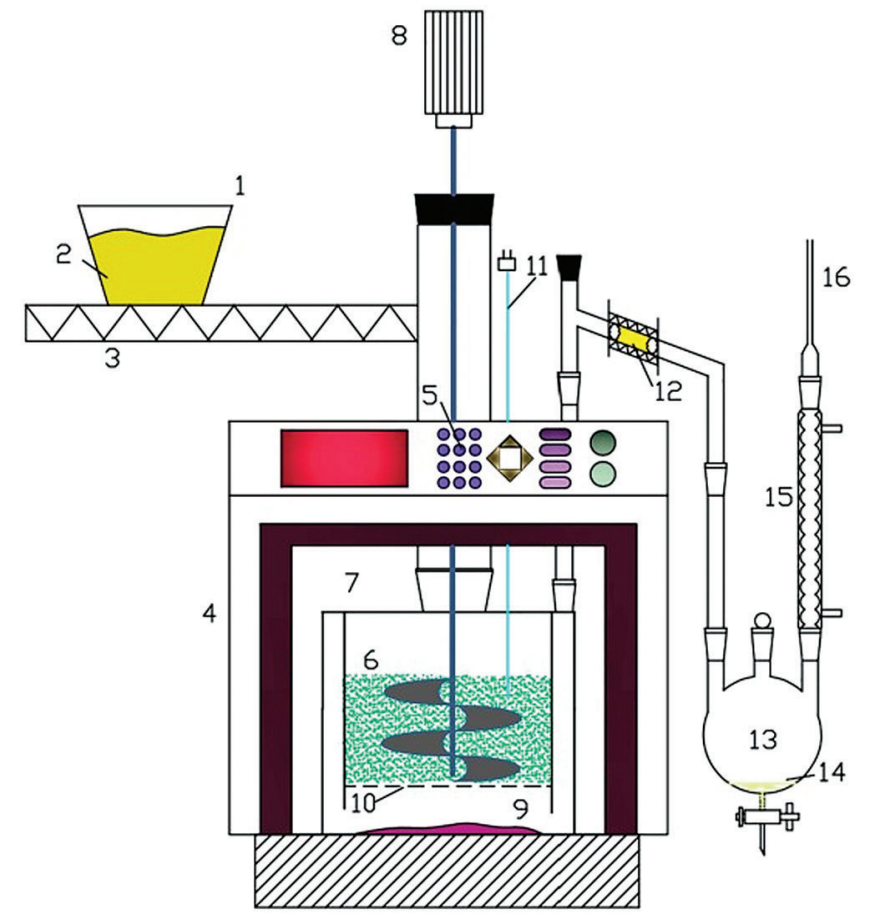

Figure 5: Schematic diagram of microwave-assisted torrefaction system [29]

Table 1: Comparison of general torrefaction technique

\begin{tabular}{lllll}
\hline Types & $\begin{array}{l}\text { Temperature } \\
\left({ }^{\circ} \mathrm{C}\right)\end{array}$ & Heating rate & Pressure & Reaction time \\
\hline Slow torrefaction & $350 \sim 800$ & $<10^{\circ} \mathrm{C} / \mathrm{min}$ & Atmospheric & Few seconds $\sim$ hours \\
$\begin{array}{l}\text { Fast torrefaction } \\
400 \sim 600\end{array}$ & $\sim 1000{ }^{\circ} \mathrm{C} / \mathrm{s}$ & vacuum $\sim$ Atmospheric & Few seconds \\
$\begin{array}{l}\text { Catalytic torrefaction } \\
\begin{array}{l}\text { Microwave- } \\
\text { torrefaction }\end{array}\end{array}$ & $700 \sim 1500$ & Medium $\sim$ fast & $\geq$ Atmospheric & Few seconds $\sim$ minutes \\
\hline
\end{tabular}




\subsection{Critical Parameters Affecting Biomass Torrefaction}

Temperature, residence time, heating rate and pyrolysis atmosphere including the low or free $\mathrm{O}_{2}, \mathrm{~N}_{2}, \mathrm{Ar}$, $\mathrm{CO}_{2}$ have been regarded the main factors affecting the torrefaction process and biochar properties [33,34]. Especially, temperature represents the factor that directly affects the torrefaction severity of biomass. Dehydration and devolatilization are the main reaction pathways of biomass at low temperature range, while carbon is the main component and is recovered with a high mass density at higher temperature. Thus, biochar contains higher fixed carbon, because the reduction of oxygen and hydrogen elements, and the coalification degree of biochar is also improved [35]. On the other hand, by increasing the residence time, the conversion of biomass at certain temperature can be maintained and enhanced [36]. The heating rate is another factor affecting the mass distribution of biochar, bio-oil and gas. At a higher heating rate, bio-oil are the mainly products, because the depolymerization of feedstock is dominant in a short time, and the formation of secondary biochar is blocked, leading to a lower yield of biochar. With the torrefaction severity, the gas environment represents other factors like the species and gas flow rate [36]. For example, the gas $\mathrm{N}_{2}$ and $\mathrm{CO}_{2}$ can show different effect on the product distribution, and a high gas flow rate can facilitate the condensed gas and char formation. In addition, the types of feedstock represent another key factor during torrefaction. For example, agricultural waste with high component of cellulose and hemicellulose can result in a low biochar yield since the volatile matters high, which can be easily degraded low temperature range of $200-300^{\circ} \mathrm{C}$ (Fig. 6). However, the high lignin content feedstock can lead to a high biochar yield since decomposition happens at higher temperature range and aromatic structures require more energy to open up the structures between them [37]. However, the physicochemical properties of biochar can also be influenced by the feedstock. For feedstock with high protein and ash content, the degradation of the cellulose or lignin will be changed. The basic carbon structure, the morphology and structural composition of biochar can be affected, such as the graphitization degree, crystallinity, and surface groups of biochar [38].

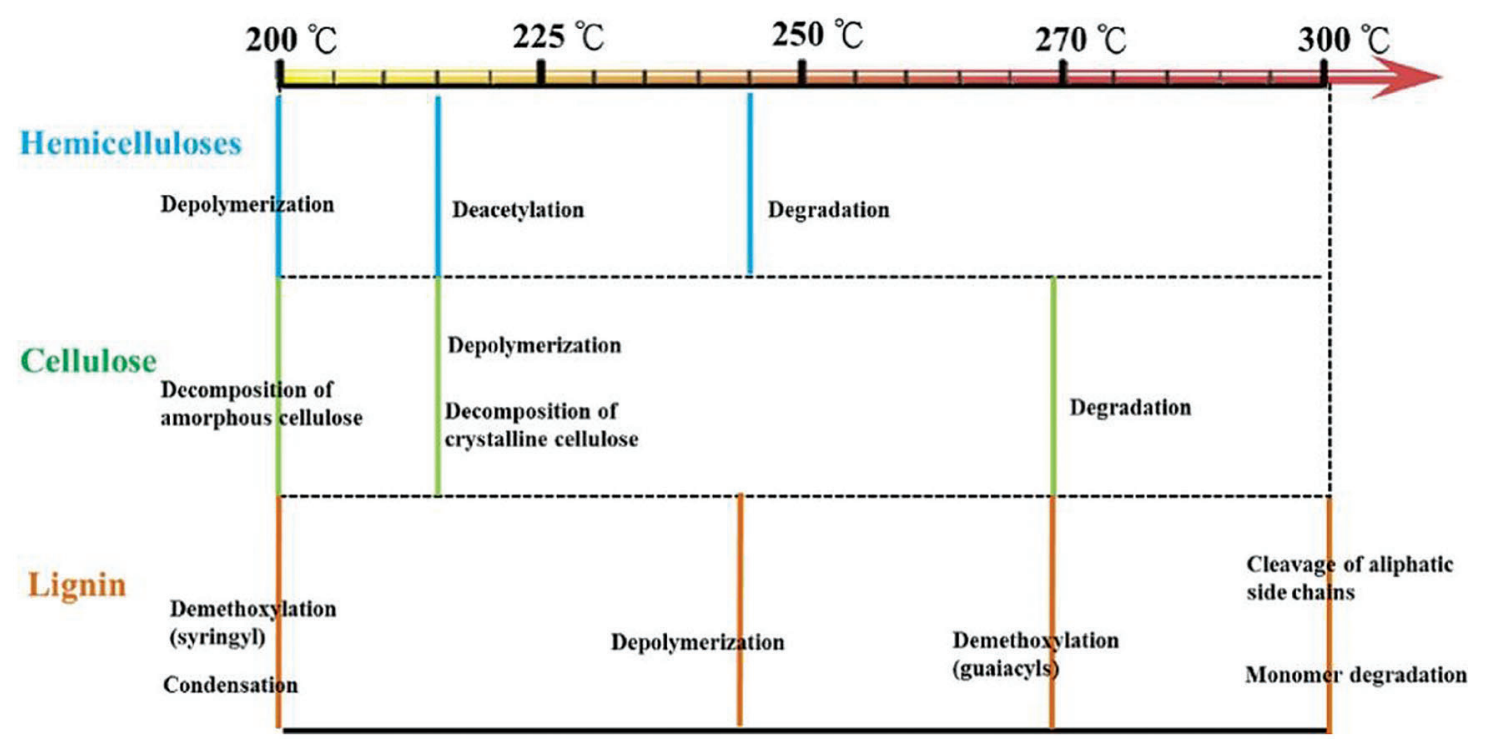

Figure 6: Single component of lignocellulose mechanism degradation during torrefaction [14]

\subsection{Formation Mechanism of Biochar for Lignocellulose Torrefaction}

The formation of biochar during torrefaction refers to the pyrolysis of feedstock and the transformation and generation of carbon condensing process. Fig. 7 shows the mechanism of biomass and the formation process of biochar. Torrefaction is generally interpreted as the intramolecular and intermolecular 
rearrangement, and biochar presents a polycyclic aromatic structure, which makes it higher carbon ratio and thermal stability. Therefore, these rearrangement reactions are generally accompanied by the release of moisture or non-condensable gases [39]. Depolymerization refers to the breakage of the bonds between the monomer units in polymers. For each break, a stabilization reaction occurs at the two new chain ends. Depolymerization can result in a reduction of the polymerization degree of the chain, until the molecules are converted into volatile substances. These molecules are condensable at ambient temperatures and are generally generated in liquid fractions such as derived monomers, dimers, or trimers. Fragmentation refers to the crack of polymers which are formed by covalent bonds into non-condensable gases and a wide variety of small chain organic compounds that can be recondensed at ambient temperature [40].

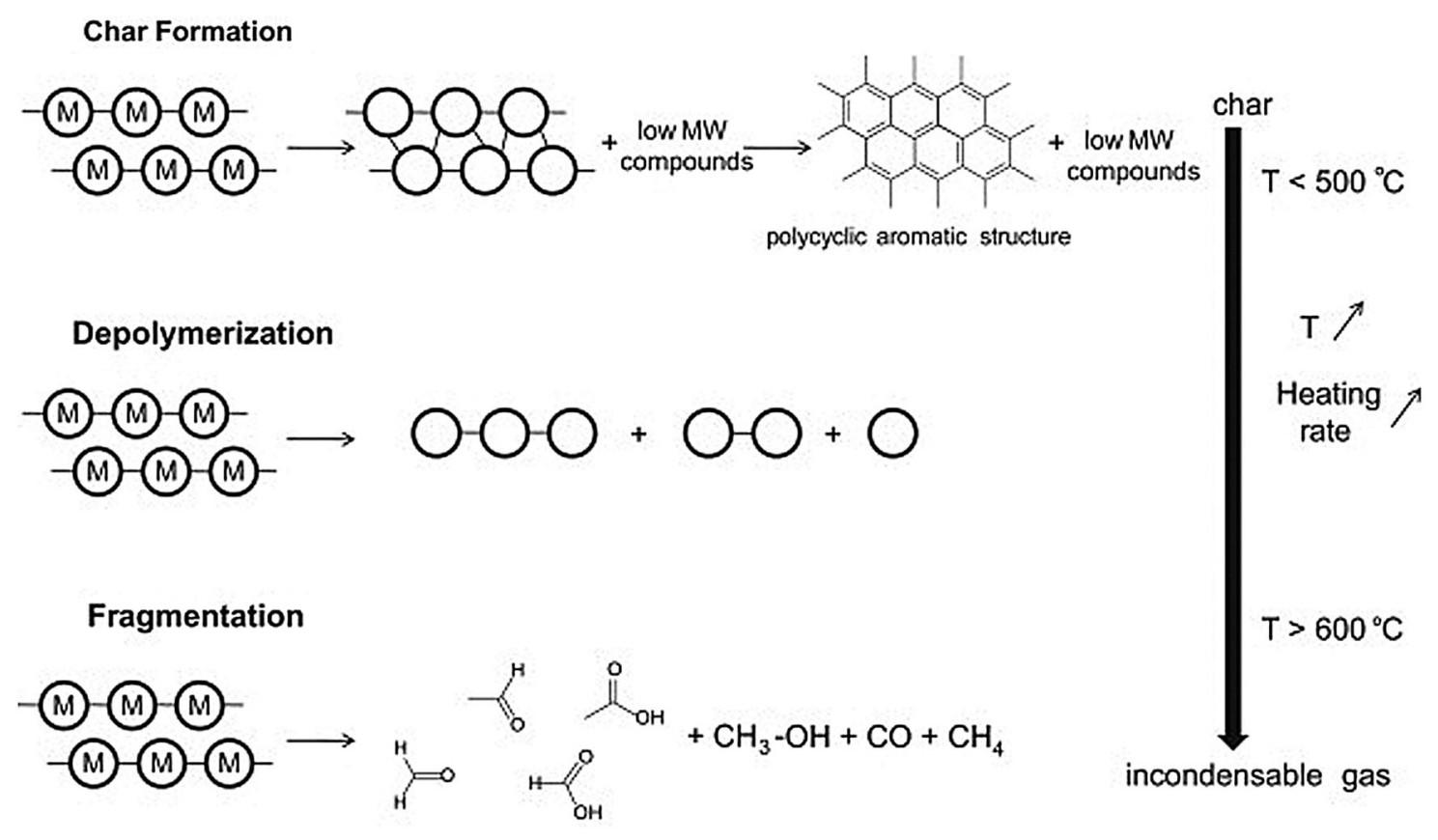

Figure 7: Formation pathways of biochar formation and conversion during torrefaction [42]

The cleavage reaction means the breakage of the chemical bonds that lead to the formation of molecules with lower weight molecular. Chemical bond breakage in polymers is similar to that of volatile compounds, and recombination or condensation reaction can lead to the combination of compounds which will further produce substances of higher molecular weight [41]. The formation mechanism of secondary biochar refers to the secondary reactions such as pyrolysis or recombination when volatile compounds are released under unstable conditions like various temperature, as shown in Fig. 7 [42]. Thus, this reaction can lead to the formation of secondary biochar when recombination occurs in the pores of the particles. The presence of polycyclic aromatic hydrocarbons in the gas phase is one way to produce secondary biochar by condensation reaction [42].

\section{Biochar Applications in Soil Amendment}

\subsection{Physicochemical Properties Improvement of Soil}

Since the preparation of biochar can be affected by thermal conversion parameters and feedstock as described above, the biochar can present diverse properties like the surface area, porosity, charge, particle size, and surface functional groups. The unique properties will bring improvement of physicochemical properties for soil such as increasing soil $\mathrm{pH}$, cation exchange capacity (CEC), soil buffering, and 
porosity. Thus, the preparation process of biochar will play important role on both biochar and soil properties. For example, in Zama et al.'s study [43], the biochar prepared from mulberry wood had increasing surface area from 16.5 to $58.0 \mathrm{~m}^{2} \mathrm{~g}^{-1}$, when the torrefaction temperature increased from $350^{\circ} \mathrm{C}$ to $550^{\circ} \mathrm{C}$, respectively. It reported that the water content available of biochar amended soil was higher than that of solo soil, and the moisture uptake by plant can also rely on the biochar dosage [44]. In addition to that, studies suggested that the biochar could trigger increase of soil $\mathrm{pH}$ due to the alkaline $\mathrm{pH}$ of biochar, which was closely related to the torrefaction time and temperature [45-47]. Chintala et al. [47] discovered another reason for $\mathrm{pH}$ increase in biochar-amended soils, which was the occurrence of negatively charged phenolic, carboxyl and hydroxyl groups on the surface of biochar which may account for the $\mathrm{pH}$ increase by binding $\mathrm{H}^{+}$ions. Meanwhile, the silicates, carbonates and bicarbonates in biochar are also regarded the reason for $\mathrm{pH}$ increase, so the acidic soil species will be amended [48]. Coincidentally, the cation exchange capacity (CEC) can also be raised due the fact that this reduces the leaching of base cations by improved binding to negatively charged functional sites of organic matter [49]. However, the high fixed carbon could lead to a decrease of CEC due to the oxygen loss at high temperature [50].

\subsection{Soil Microbiology Change}

When biochar was mixed with soil, the soil performances including $\mathrm{pH}$, water holding ability and nutrients should be modified with the microbial species. In Hua et al.' study [51], biochar from wheat straw and fruit tree significantly influenced the microbial community structure at the phylum level, since the soil $\mathrm{pH}, \mathrm{TOC}$ and $\mathrm{Sb}$ (element $\mathrm{T}$ ) were changed. In some works, even different particle sizes of the biochar exhibited various effect on the microbial community. Chen et al. [52] found that fine-sized biochar can significantly increase the total microbial phospholipid fatty acids concentrations by $60.28 \%$ and $88.94 \%$ than that from the medium and coarse particles of biochar prepared from bamboo. Yang et al. [53] reported that the bacterial and fungal diversity indices in soli were generally higher for biochar than that of biochar-based fertilizer and fertilizer, while the biochar-based fertilizer can alter the soil microbial community and enhanced some plant growth-promoting microbes according to the cluster analysis. Thus, biochar can facilitate the soil friendly microbes, and the combination with other fertilizers or nutrients will boost the function of biochar. Li et al. [54] used meta-analysis to investigate the responses of soil microbial biomass and diversity aroused by the biochar addition, and their work indicated that total bacterial and fungal biomass, and microbial diversity were increased more by biochar prepared from low temperature or nutrients rich feedstocks, and the results were also different in sandy from that in clay soils. Igalavithana et al. [55] investigated the efficacy biochar obtained from vegetable waste and pine cone about the abundance of microbial community in soil, and the torrefied biomass can significantly increase both microbial community and dehydrogenase activity. The soil microbial community also presents interactions by contaminants like heavy metals, antibiotic species with biochar used in soil. For instance, Wang et al. [56] reported that the biochar addition can raise the relative content of Fe reducing bacteria and As reducing functional genes, when biochar was used in As-contaminated paddy soil. Thus, the alterations of soil physico-chemical properties after biochar assisted remediation will promote the microbial abundance and activities, and the abundance, species, activity and the interactions with biochar of microbial community depend on the soil species, contaminants, and the biochar properties. Adjustment of biochar preparation conditions is essential to get desirable properties to fit microbial community in soil.

\subsection{Nutrition and Fertility Improvement of Soil}

Since the torrefaction process can also recover part $\mathrm{N}$ and $\mathrm{P}$ and etc. in biochar, the nutrient release rates of soil can be raised, especially by using biochar obtained from poultry manure. It has been recognized that nutrition and fertility of the soil can be influenced by the biochar type, the dose of the biochar, mixing depth, nutrients availability, plant species and soil texture [57]. Ibn Ferjani et al. [58] reported that only 5\% of 
biochar addition in the agricultural soil can raise the water leached $\mathrm{N}$ and $\mathrm{K}$ by about $181 \%$ and $521 \%$, while the $\mathrm{K}$, the $\mathrm{Na}$ and $\mathrm{Ca}$ were transformed into more leachable and plant available forms. Generally, the content of nutrients for bioavailability in biochar is increased, and this improves the utilization of crops from soil. Yan et al. [59] found that biochar derived from bamboo and rice benefited the tea growth by improving soil fertility, since the $\mathrm{pH}$ and available $\mathrm{P}, \mathrm{K}$, and $\mathrm{Mg}$ content of acidic soil was increased. However, the nutrient uptake by plants also depends on the specific plant species and growing environment. For instance, $\mathrm{Wu}$ et al. [60] suggested that the phosphorus uptake was reduced by Phragmites australis, since the interception of $\mathrm{P}$ by the iron plaque and the concentration of soil available $\mathrm{P}$ was decreased. Meanwhile, the proper dosage of biochar is also crucial for nutrients in soil for crops uptake. Abdul et al. found that the germination percentage was low since a higher percentage of biochar in soil would maximize the water holding capacity and the biochar will contain the nutrients. Moreover, the physical properties of biochar can also affect the nutrients release in soil. Here, we have discussed in the above section the physical properties.

\subsection{Heavy Metal Contaminates in Soil}

As for the remediation of heavy metals in soil, biochar has showed potential role as confirmed by numerous studies. Different from organic contaminants, the absorption ability of biochar may ultimately enhance the persistence in the soil environment since they will be protected from microbial degradation. Studies have proved that preparation parameters like temperature and residence time can affect the porosity of biochar, so it will further affect the soil response, biochar addition, and heavy metals [61]. Therefore, most studies have focused on the mobility and interactions with heavy metals in soil. Potential mechanism for interactions like electrostatic attraction, ion exchange, complexation and precipitation, between biochar and heavy metals in soils have been divided into direct interactions and indirect interactions (Fig. 8).

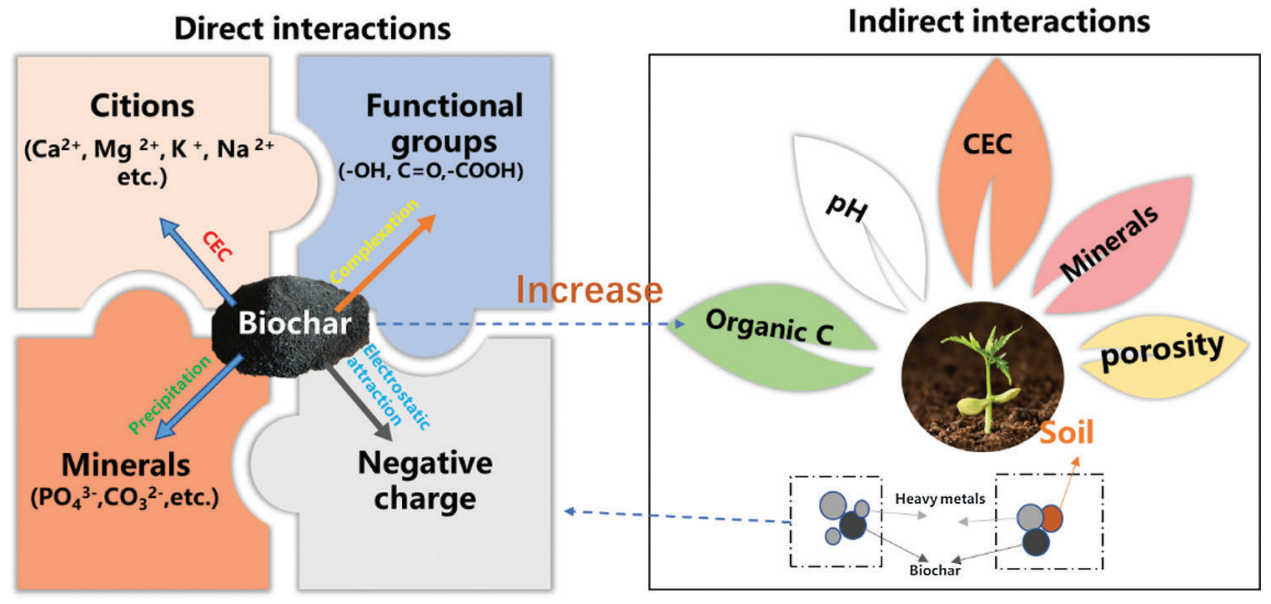

Figure 8: The potential mechanism for the interactions between biochar and heavy metals

In Ahmad et al.'s [62] work, the result showed that biochar facilitated the electrostatic attraction of positively charged ions. It has also been proved that the attraction depended on the surface charge of the chemical groups like the oxygen-containing groups on biochar [63]. In addition, biochar shows high cation exchange capability and releases $\mathrm{Ca}$ (II) and $\mathrm{Mg}$ (II), and this provides environment to exchange with heavy metal ions on biochar surfaces. For example, the high cation exchange capability of biochar can enhance the immobilization of Cd (II) [64]. Unlike cation exchange capability, the complexation is another way for direct interaction. El-Naggar et al. [65] investigated the multi-contaminated soils by As, 
$\mathrm{Cd}, \mathrm{Pb}$, and $\mathrm{Zn}$ with biochar made from grass residues, rice straw, and wood, and the result indicated that the mobilization of $\mathrm{Cd}$ and $\mathrm{Zn}$ was limited, while the As and $\mathrm{Pb}$ can be negatively affected by the surface groups including phenolic hydroxyl and carboxylic groups. Additionally, the mobilization and phytoavailability depended on the dissolved aliphatic- and aromatic-carbon, chloride, sulfur chemistry, phosphate competition, and the electrostatic repulsion of biochar mixed soils. In Ahmad et al.'s study [66], the biochar can form insoluble and stable metal complexes with $\mathrm{Fe}(\mathrm{II})$ and $\mathrm{Mn}(\mathrm{II})$, and the mobility was also decreased. Except for that, the precipitation produced from heavy metals and biochar is another way, since insoluable compounds can be formed. In Liang et al.'s study [67], P-containing precipitation was observed when high $\mathrm{P}$ content biochar was used for reacted with the element $\mathrm{Pb}$ contaminated soil. Thus, it can be concluded that the feedstock, production parameters and biochar properties will affect the binding pathways between biochar and the heavy metals. In addition to the direct interactions, the biochar can affect the behaviors of heavy metals in soil through adjusting the $\mathrm{pH}$, changing the organic carbon, soil CEC, as well as the mineral composition, and then poses effect on the mobility and bioavailability.

\section{Future Perspectives and Conclusion}

This review summarized the recent progress in agricultural waste torrefaction techniques and potential applications in soil remediation. The effects of different pyrolysis pathways on the biochar formation and properties were elaborated, coupled with the effects of critical parameters. Conversion and mechanisms of biochar prepared from agricultural wastes with lignocellulosic material as typical component were discussed, and biochar prepared for altering soil quality with relation to physicochemical characteristics, microbial community characteristics, nutrients, and the stability and degradation of soil pollutants like heavy metals were compared. The technical challenges of soil remediation based on agricultural waste derived biochar were excepted, and potential future perspectives and challenges are given below:

(a) Since the preparation of biochar derived from torrefaction carbonization process, the post applications in soil contains toxic substances such as polycyclic aromatic hydrocarbons, $\mathrm{N}$-containing compounds from should be further investigated.

(b) Long term stability and the effect for biochar addition on the degradation and immobilization of contaminants in soil should be concerned, coupled with the dynamics study. Biochar aging and the effect on the soil properties can be investigated along with the nutrients, contaminants, and etc.

(c) Multiple disciplines, techniques, and data processing techniques should be used for identifying the mechanisms responsible for the soil remediation with biochar.

(d) The feedstocks are more diverse and complex for biochar preparation, and the torrefaction mechanism needs further understanding the biochar formation and proper control desirable properties.

(e) The plant growth can be affected by the biochar remediated from soil, so it is essential to track the nutrients uptake pathways, heavy metals distributions and detail transformation in plant. And the soil electrochemistry induced by biochar between the microflora and soil should be focused in future.

Funding Statement: This study is supported by Sichuan Science and Technology Program (2021YFS0284, 2018SZDZX0026, 2021YFS0289) and the Opening Project of Key Laboratory of Theoretical Chemistry of Environment (South China Normal University), Ministry of Education (20200103).

Conflicts of Interest: The authors declare that they have no conflicts of interest to report regarding the present study. 


\section{References}

1. Cai, X., Yuan, Y., Yu, L., Zhang, B., Li, J. et al. (2020). Biochar enhances bioelectrochemical remediation of pentachlorophenol-contaminated soils via long-distance electron transfer. Journal of Hazardous Materials, 391, 122213. DOI 10.1016/j.jhazmat.2020.122213.

2. Wang, M., Zhu, Y., Cheng, L., Andserson, B., Zhao, X. et al. (2018). Review on utilization of biochar for metalcontaminated soil and sediment remediation. Journal of Environmental Sciences, 63, 156-173. DOI 10.1016/j. jes.2017.08.004.

3. Beesley, L., Moreno-Jiménez, E., Gomez-Eyles, J. L., Harris, E., Robinson, B. et al. (2011). A review of biochars' potential role in the remediation, revegetation and restoration of contaminated soils. Environmental Pollution, 159(12), 3269-3282. DOI 10.1016/j.envpol.2011.07.023.

4. Sohi, S., Lopez-Capel, E., Krull, E., Bol, R. (2009). Biochar, climate change and soil: A review to guide future research. CSIRO Land and Water Science Report, 5(9), 17-31.

5. Atkinson, C. J., Fitzgerald, J. D., Hipps, N. A. (2010). Potential mechanisms for achieving agricultural benefits from biochar application to temperate soils: A review. Plant and Soil, 337(1-2), 1-18. DOI 10.1007/s11104010-0464-5.

6. Mante, O. D., Agblevor, F. A. (2011). Catalytic conversion of biomass to bio-syncrude oil. Biomass Convers Biorefinery, 1(4), 203-215. DOI 10.1007/s13399-011-0020-4.

7. Falco, C., Baccile, N., Titirici, M. M. (2011). Morphological and structural differences between glucose, cellulose and lignocellulosic biomass derived hydrothermal carbons. Green Chemistry, 13(11), 3273-3281. DOI 10.1039/ clgc15742f.

8. Nguyen, B. T., Lehmann, J., Kinyangi, J., Smernik, R., Riha, S. J. et al. (2008). Long-term black carbon dynamics in cultivated soil. Biogeochemistry, 89(3), 295-308. DOI 10.1007/s10533-008-9220-9.

9. Warnock, D. D., Lehmann, J., Kuyper, T. W., Rillig, M. C. (2007). Mycorrhizal responses to biochar in soilConcepts and mechanisms. Plant and Soil, 300(1-2), 9-20. DOI 10.1007/s11104-007-9391-5.

10. Lehmann, J., Rillig, M. C., Thies, J., Masiello, C. A., Hockaday, W. C. et al. (2011). Biochar effects on soil biotaA review. Soil Biology \& Biochemistry, 43(9), 1812-1836. DOI 10.1016/j.soilbio.2011.04.022.

11. Ren, J., Wang, F., Zhai, Y., Zhu, Y., Peng, C. et al. (2011). Effect of sewage sludge hydrochar on soil properties and Cd immobilization in a contaminated soil. Chemosphere: Global Change Science, 189, 627-633. DOI 10.1016/j. chemosphere.2017.09.102.

12. Reza, M. T., Andert, J., Wirth, B., Busch, D., Pielert, J. et al. (2014). Hydrothermal carbonization of biomass for energy and crop production. Applied Bioenergy, 1(1), 11-19. DOI 10.2478/apbi-2014-0001.

13. Sun, R. C. (2010). Cereal straw as a resource for sustainable biomaterials and biofuels. The Netherlands: Elsevier.

14. Chen, W. H., Lin, B. J., Lin, Y. Y., Chu, Y. S., Ubando, A. T. et al. (2020). Progress in biomass torrefaction: Principles, applications and challenges. Progress in Energy and Combustion Science, 82(2), 100887. DOI 10.1016/j.pecs.2020.100887.

15. Laureano-Perez, L., Teymouri, F., Alizadeh, H., Dale, B. E. (2009). Understanding factors that limit enzymatic hydrolysis of biomass. Applied Biochemistry and Biotechnology, 124(1-3), 1081-1099. DOI 10.1385/ ABAB:124:1-3:1081.

16. Feldman, D. (1985). Wood-chemistry, ultrastructure, reactions. Berlin and New York: Wiley.

17. Collard, F. X., Blin, J. (2014). A review on pyrolysis of biomass constituents: Mechanisms and composition of the products obtained from the conversion of cellulose, hemicelluloses and lignin. Renewable \& Sustainable Energy Reviews, 38, 594-608. DOI 10.1016/j.rser.2014.06.013.

18. Chaiwong, K., Kiatsiriroat, T., Vorayos, N., Thararax, C. (2009). Study of bio-oil and bio-char production from algae by slow pyrolysis. Biomass and Bioenergy, 56(7), 600-606. DOI 10.1016/j.biombioe.2013.05.035.

19. Roddy, D. J., Manson-Whitton, C. (2012). Biomass gasification and pyrolysis. Comprehensive Renewable Energy, 5(1), 133-153. DOI 10.1016/B978-0-08-087872-0.00514-X. 
20. Chiodo, V., Zafarana, G., Maisano, S., Freni, S., Urbani, F. (2016). Pyrolysis of different biomass: Direct comparison among Posidonia Oceanica, Lacustrine Alga and White-Pine. Fuel, 164, 220-227. DOI 10.1016/j. fuel.2015.09.093.

21. Miao, X., Wu, Q., Yang, C. (2004). Fast pyrolysis of microalgae to produce renewable fuels. Journal of Analytical and Applied Pyrolysis, 71(2), 855-863. DOI 10.1016/j.jaap.2003.11.004.

22. Hang, S. C., Yeon, S. C., Hoon, C. P. (2011). Fast pyrolysis characteristics of lignocellulosic biomass with varying reaction conditions. Renewable Energy, 42, 131-135. DOI 10.1016/j.renene.2011.08.049.

23. Budsaereechai, S., Hunt, A. J., Ngernyen, Y. (2019). Catalytic pyrolysis of plastic waste for the production of liquid fuels for engines. RSC Advances, 9(10), 5844-5857. DOI 10.1039/C8RA10058F.

24. Babich, I. V., Hulst, M., Lefferts, L., Moulijn, J. A., O'Connor, P. et al. (2011). Catalytic pyrolysis of microalgae to high-quality liquid bio-fuels. Biomass and Bioenergy, 35(7), 3199-3207. DOI 10.1016/j.biombioe.2011.04.043.

25. Thangalazhy-Gopakumar, S., Adhikari, S., Gupta, R. B., Tu, M., Taylor, S. (2011). Production of hydrocarbon fuels from biomass using catalytic pyrolysis under helium and hydrogen environments. Bioresource Technology, 102(12), 6742-6749. DOI 10.1016/j.biortech.2011.03.104.

26. Thangalazhy-Gopakumar, S., Adhikari, S., Chattanathan, S. A., Gupta, R. B. (2012). Catalytic pyrolysis of green algae for hydrocarbon production using H+ZSM-5 catalyst. Bioresource Technology, 118, 150-157. DOI 10.1016/ j.biortech.2012.05.080.

27. Wang, K., Brown, R. C. (2013). Catalytic pyrolysis of microalgae for production of aromatics and ammonia. Green Chemistry, 15(3), 675-681. DOI 10.1039/c3gc00031a.

28. Chen, C., Cheng, Z., Xu, Q., Qin, S. (2018). Study on the microwave catalytic pyrolysis characteristics and energy consumption analysis of oil shale. IOP Conference Series Earth and Environmental Science, 133, 012021. DOI 10.1088/1755-1315/133/1/012021.

29. Zhou, J., Liu, S., Zhou, N., Fan, L., Zhang, Y. et al. (2018). Development and application of a continuous fast microwave pyrolysis system for sewage sludge utilization. Bioresource Technology, 256(1), 295-301. DOI 10.1016/j.biortech.2018.02.034.

30. Li, L., Ma, X., Xu, Q., Hu, Z. (2013). Influence of microwave power, metal oxides and metal salts on the pyrolysis of algae. Bioresource Technology, 142(2), 469-474. DOI 10.1016/j.biortech.2013.05.080.

31. Beneroso, D., Bermúdez, J. M., Arenillas, A., Menéndez, J. A. (2013). Microwave pyrolysis of microalgae for high syngas production. Bioresource Technology, 144, 240-246. DOI 10.1016/j.biortech.2013.06.102.

32. Hu, Z., Ma, X., Chen, C. (2013). A study on experimental characteristic of microwave-assisted pyrolysis of microalgae. Bioresource Technology, 107, 487-493. DOI 10.1016/j.biortech.2011.12.095.

33. Xu, X., Li, Z., Jiang, E. (2019). Torrefaction performance of camellia shell under pyrolysis gas atmosphere. Bioresource Technology, 284(23), 178-187. DOI 10.1016/j.biortech.2019.03.091.

34. Yang, H., Yan, R., Chen, H., Lee, D. H., Zheng, C. (2006). Characteristics of hemicellulose, cellulose and lignin pyrolysis. Fuel, 86(12-13), 1781-1788. DOI 10.1016/j.fuel.2006.12.013.

35. Manyà, J. J. (2012). Pyrolysis for biochar purposes: A review to establish current knowledge gaps and research needs. Environmental Science \& Technology, 46(15), 7939-7954. DOI 10.1021/es301029g.

36. Kan, T., Strezov, V., Evans, T. J. (2016). Lignocellulosic biomass pyrolysis: A review of product properties and effects of pyrolysis parameters. Renewable \& Sustainable Energy Reviews, 57(28), 1126-1140. DOI 10.1016/j. rser.2015.12.185.

37. Dhyani, V., Bhaskar, T. (2018). A comprehensive review on the pyrolysis of lignocellulosic biomass. Renewable Energy, 129, 695-716. DOI 10.1016/j.renene.2017.04.035.

38. Liu, W. J., Li, W. W., Jiang, H., Yu, H. Q. (2017). Fates of chemical elements in biomass during its pyrolysis. Chemistry Reviews, 117(9), 6367-6398. DOI 10.1021/acs.chemrev.6b00647.

39. van de Velden, M., Baeyens, J., Brems, A., Janssens, B., Dewil, R. (2010). Fundamentals, kinetics and endothermicity of the biomass pyrolysis reaction. Renewable Energy, 35(1), 232-242. DOI 10.1016/j. renene.2009.04.019. 
40. Wooten, J. B., Seeman, J. I., Hajaligol, M. R. (2004). Observation and characterization of cellulose pyrolysis intermediates by 13C CPMAS NMR. A new mechanistic model. Energy and Fuels, 18(1), 1-15. DOI 10.1021/ ef0300601.

41. Hosoya, T., Kawamoto, H., Saka, S. (2009). Role of methoxyl group in char formation from lignin-related compounds. Journal of Analytical and Applied Pyrolysis, 84(1), 79-83. DOI 10.1016/j.jaap.2008.10.024.

42. Elyounssi, K., Collard, F. X., Mateke, J. A. N., Blin, J. (2011). Improvement of charcoal yield by two-step pyrolysis on eucalyptus wood: A thermogravimetric study. Fuel, 90(7), 161-167. DOI 10.1016/j.fuel.2012.01.030.

43. El-Naggar, A., El-Naggar, A. H., Shaheen, S. M., Sarkar, B., Chang, S. X. et al. (2019). Biochar compositiondependent impacts on soil nutrient release, carbon mineralization, and potential environmental risk: A review. Journal of Environmental Management, 241(1), 458-467. DOI 10.1016/j.jenvman.2019.02.044.

44. Peake, L. R., Reid, B. J., Tang, X. (2014). Quantifying the influence of biochar on the physical and hydrological properties of dissimilar soils. Geoderma, 235-236, 182-190. DOI 10.1016/j.geoderma.2014.07.002.

45. Glaser, B., Lehmann, J., Zech, W. (2002). Ameliorating physical and chemical properties of highly weathered soils in the tropics with charcoal-A review. Biology and Fertility of Soils, 35(4), 219-230. DOI 10.1007/s00374-002-0466-4.

46. Farrell, M., Kuhn, T. K., Macdonald, L. M., Maddern, T. M., Murphy, D. V. et al. (2013). Microbial utilisation of biochar-derived carbon. Science of the Total Environment, 465(6), 288-297. DOI 10.1016/j.scitotenv.2013.03.090.

47. Chintala, R., Schumacher, T. E., Kumar, S., Malo, D. D., Rice, J. A. et al. (2014). Molecular characterization of biochars and their influence on microbiological properties of soil. Journal of Hazardous Materials, 279, 244-256. DOI 10.1016/j.jhazmat.2014.06.074.

48. Stewart, C. E., Zheng, J., Botte, J., Cotrufo, M. F. (2013). Co-generated fast pyrolysis biochar mitigates greenhouse gas emissions and increases carbon sequestration in temperate soils. Global Change Biology Bioenergy, 5(2), 153-164. DOI 10.1111/gcbb.12001.

49. Ducey, T. F., Ippolito, J. A., Cantrell, K. B., Novak, J. M., Lentz, R. D. (2013). Addition of activated switchgrass biochar to an aridic subsoil increases microbial nitrogen cycling gene abundances. Applied Soil Ecology, 65(2), 65-72. DOI 10.1016/j.apsoil.2013.01.006.

50. Huff, M. D., Kumar, S., Lee, J. W. (2014). Comparative analysis of pinewood, peanut shell, and bamboo biomass derived biochars produced via hydrothermal conversion and pyrolysis. Journal of Environmental Management, 146(3), 303-308. DOI 10.1016/j.jenvman.2014.07.016.

51. Hua, L., Wu, C., Zhang, H., Cao, L., Wei, T. et al. (2021). Biochar-induced changes in soil microbial affect species of antimony in contaminated soils. Chemosphere, 263, 127795. DOI 10.1016/j.chemosphere.2020.127795.

52. Chen, J., Li, S., Liang, C., Xu, Q., Li, Y. et al. (2017). Response of microbial community structure and function to short-term biochar amendment in an intensively managed bamboo (Phyllostachys praecox) plantation soil: Effect of particle size and addition rate. Science of the Total Environment, 574, 24-33. DOI 10.1016/j. scitotenv.2016.08.190.

53. Yang, W., Li, C., Wang, S., Zhou, B., Mao, Y. et al. (2021). Influence of biochar and biochar-based fertilizer on yield, quality of tea and microbial community in an acid tea orchard soil. Applied Soil Ecology, 166, 104005. DOI 10.1016/j.apsoil.2021.104005.

54. Li, X., Wang, T., Chang, S. X., Jiang, X., Song, Y. (2020). Biochar increases soil microbial biomass but has variable effects on microbial diversity: A meta-analysis. Science of the Total Environment, 749, 141593. DOI 10.1016/j.scitotenv.2020.141593.

55. Igalavithana, A. D., Lee, S. E., Lee, Y. H., Tsang, D. C. W., Rinklebe, J. et al. (2017). Heavy metal immobilization and microbial community abundance by vegetable waste and pine cone biochar of agricultural soils. Chemosphere, 174, 593-603. DOI 10.1016/j.chemosphere.2017.01.148.

56. Wang, N., Xue, X. M., Juhasz, A. L., Chang, Z. Z., Li, H. B. (2017). Biochar increases arsenic release from an anaerobic paddy soil due to enhanced microbial reduction of iron and arsenic. Environmental Pollution, 220, 514-522. DOI 10.1016/j.envpol.2016.09.095.

57. Yuan, P., Wang, J., Pan, Y., Shen, B., Wu, C. (2019). Review of biochar for the management of contaminated soil: Preparation, application and prospect. Science of the Total Environment, 659, 473-490. DOI 10.1016/j. scitotenv.2018.12.400. 
58. Ibn Ferjani, A., Jellali, S., Akrout, H., Limousy, L., Hamdi, H. et al. (2020). Nutrient retention and release from raw exhausted grape marc biochars and an amended agricultural soil: Static and dynamic investigation. Environmental Technology \& Innovation, 19, 100885. DOI 10.1016/j.eti.2020.100885.

59. Yan, P., Shen, C., Zou, Z., Fu, J., Li, X. et al. (2021). Biochar stimulates tea growth by improving nutrients in acidic soil. Scientific Horticulture, 283(7), 110078. DOI 10.1016/j.scienta.2021.110078.

60. Wu, J., Huang, R., Zhou, Q., Lu, H., Li, F. et al. (2021). Magnetic biochar reduces phosphorus uptake by Phragmites australis during heavy metal remediation. Science of the Total Environment, 758, 143643. DOI 10.1016/j.scitotenv.2020.143643.

61. Yang, C., Liu, J., Lu, S. (2021). Pyrolysis temperature affects pore characteristics of rice straw and canola stalk biochars and biochar-amended soils. Geoderma, 397(9), 115097. DOI 10.1016/j.geoderma.2021.115097.

62. Ahmad, Z., Gao, B., Mosa, A., Yu, H., Yin, X. et al. (2018). Removal of $\mathrm{Cu}(\mathrm{II}), \mathrm{Cd}(\mathrm{II})$ and $\mathrm{Pb}(\mathrm{II})$ ions from aqueous solutions by biochars derived from potassium-rich biomass. Journal of Cleaner Production, 180(100), 437-449. DOI 10.1016/j.jclepro.2018.01.133.

63. Cho, H. H., Wepasnick, K., Smith, B. A., Bangash, F. K., Fairbrother, D. H. (2010). Sorption of aqueous Zn[II] and $\mathrm{Cd}[\mathrm{II}]$ by multiwall carbon nanotubes: The relative roles of oxygen-containing functional groups and graphenic carbon. Langmuir, 26(2), 967-981. DOI 10.1021/la902440u.

64. Lei, S., Shi, Y., Qiu, Y., Che, L., Xue, C. (2019). Performance and mechanisms of emerging animal-derived biochars for immobilization of heavy metals. Science of the Total Environment, 646, 1281-1289. DOI 10.1016/ j.scitotenv.2018.07.374.

65. El-Naggar, A., Lee, M. H., Hur, J., Lee, Y. H., Igalavithana, A. D. et al. (2020). Biochar-induced metal immobilization and soil biogeochemical process: An integrated mechanistic approach. Science of the Total Environment, 698(2), 134112. DOI 10.1016/j.scitotenv.2019.134112.

66. Ahmad, M., Lee, S. S., Lim, J. E., Lee, S. E., Cho, J. S. et al. (2014). Speciation and phytoavailability of lead and antimony in a small arms range soil amended with mussel shell, cow bone and biochar: EXAFS spectroscopy and chemical extractions. Chemosphere, 95(11), 433-441. DOI 10.1016/j.chemosphere.2013.09.077.

67. Liang, Y., Cao, X., Zhao, L., Arellano, E. (2014). Biochar- and phosphate-induced immobilization of heavy metals in contaminated soil and water: Implication on simultaneous remediation of contaminated soil and groundwater. Environmental Science and Pollution Research, 21(6), 4665-4674. DOI 10.1007/s11356-013-2423-1. 